\title{
Physical Therapists' Assessment of Patient Self-Efficacy for Home Exercise Programs
}

Kelsey J Picha, PhD, ATC ${ }^{1}$, Alison Snyder Valier, PhD, ATC ${ }^{1}$, Nicholas R Heebner, PhD, ATC ${ }^{2}$, John P Abt, PhD, ATC ${ }^{3}$, Ellen L Usher, PhD², Gilson Capilouto, PhD, CCC-SLP' ${ }^{2}$ Tim L Uhl, PhD, PT ${ }^{2}$

1 Department of Interdisciplinary Health Sciences, A.T. Still University, ${ }^{2}$ College of Health Sciences, Department of Rehabilitation Sciences, University of Kentucky, ${ }^{3}$ Children's Health Andrews Institute for Orthopaedics and Sports Medicine

Keywords: therapeutics, social cognitive theory, rehabilitation, orthopedics

https://doi.org/10.26603/001c.18957

\section{International Journal of Sports Physical Therapy}

Vol. 16, Issue 1, 2021

\section{Background}

Patient adherence to home exercise programs (HEPs) is low, and poor patient self-efficacy is a barrier clinicians can influence. However, little evidence suggests that clinicians assess level of patient self-efficacy before prescribing HEPs.

\section{Purpose}

To determine the importance of patient self-efficacy to physical therapists (PTs) when addressing patient barriers, determine how PTs assess and use patient self-efficacy for HEPs, and describe the barriers facing PTs when assessing patient self-efficacy for HEPs.

\section{Study Design}

Survey.

\section{Methods}

Practicing PTs were recruited from the American Physical Therapy Association's Orthopedic Section and emailed the electronic survey.

\section{Results}

Email invitations were sent to 17730 potential participants, and 462 PTs completed the survey over one month. PTs rated self-efficacy as "very" to "extremely" important for patient adherence (58\%, 265/454). Most (71\%, 328/462) reported assessing self-efficacy before prescribing HEPs and did so through verbal discussion and observation of the patient (50\% and 38\% respectively). Half of respondents individualized HEPs through self-efficacy related themes. PTs not assessing self-efficacy reported not knowing how (51\%, 68/134), being unsure what to do with the information $(24 \%, 32 / 134)$, or reporting other barriers $(21 \%, 28 / 134)$.

\section{Conclusions}

Most PTs indicated that self-efficacy was important for patient adherence, but assessment strategies reported, such as verbal discussion and observation, may not be the most accurate. PTs who did not assess self-efficacy reported not knowing how or what to do with the information once collected. These findings suggest that there is a gap in knowledge related to how to evaluate self-efficacy for HEPs. Better assessment of self-efficacy may lead to more appropriate and effective implementation strategies.

\footnotetext{
a Corresponding author: 


\section{Level of Evidence}

Level II

\section{INTRODUCTION}

Rehabilitation is often required after musculoskeletal injury or surgery to return patients to normal function. Home exercise programs (HEPs) are one form of rehabilitation program that can contribute to patient outcomes ${ }^{1}$ and are a necessary part of recovery post injury or surgery. Although the benefits of rehabilitation are known, patient non-adherence with rehabilitation programs is $50 \%-70 \% .^{2-4}$ Lack of adherence is a significant issue because non-adherent patients have poorer outcomes than those who are adherent. ${ }^{5}$ Barriers to rehabilitation adherence include patient factors such as anxiety, depression, forgetfulness, lack of social support, low levels of activity at baseline, pain with exercise, and low self-efficacy. ${ }^{2,6}$ Addressing barriers to rehabilitation in clinical practice may produce more compliant patients and ultimately improve their outcomes.

From a healthcare and exercise perspective, low self-efficacy is a patient barrier to adherence that clinicians can positively influence. ${ }^{6,7}$ The concept of self-efficacy refers to the belief in one's capability to perform given tasks. ${ }^{8} \mathrm{Al}-$ bert Bandura theorized that 4 primary sources of information (mastery, verbal, vicarious, and physiologic/emotional state) can alter individuals' beliefs about their capabilities. ${ }^{8}$ Mastery experience refers to one's past successes, verbal or social persuasion involves encouragement or support from others, vicarious experiences refer to an individual's observation of others' success or failure, and lastly, physiological or emotional states are influenced by the body's reaction to tasks or situations. ${ }^{8}$ Researchers have used a variety of measures to evaluate self-efficacy beliefs in general and for exercise and pain, for example the Pain Self Efficacy Scale. ${ }^{9-11}$ Further, many solutions and strategies have been studied to improve self-efficacy and adherence with rehabilitation programs. ${ }^{7,9,12}$ Despite the variety and availability of interventions known to improve self-efficacy, 7,9,12 evidence to suggest improvements in patient self-efficacy and/ or adherence for HEPs has not been reported. Low self-efficacy with rehabilitation exercise warrants study because of the value it may play in increasing patient adherence, improving patient outcomes, and reducing the cost associated with rehabilitation. This gap between assessing patient self-efficacy, self-efficacy interventions, and patient outcomes, may be due to lack of assessment or lack of knowledge of assessments in clinical practice.

Currently, it is unknown whether clinicians assess selfefficacy as a routine part of standard clinical practice, especially when prescribing HEPs. A better understanding of evaluation and intervention related to self-efficacy by clinicians is needed. Therefore, the purpose of the current study was to better understand clinicians' approach to assessing patient self-efficacy when creating an HEP. Specifically, physical therapists (PTs) were surveyed to 1) determine the importance of patient self-efficacy when addressing patient barriers to rehabilitation exercise adherence, 2) examine how PTs assess and use patient self-efficacy in HEP planning, and 3) describe the barriers perceived by PTs related to the assessment of patient self-efficacy for an HEP. It was hypothesized that PTs would not recognize self-efficacy as one of the top barriers to patient adherence, would use observation to assess self-efficacy at least $50 \%$ of the time, and would report "lack of time" as the most common barrier for not assessing patient self-efficacy.

\section{METHODS}

The current study used a cross-sectional survey design and was approved by the University of Kentucky Institutional Review Board. Study participants were recruited through the Academy of Orthopaedic Physical Therapy. To be included in data analysis, participants had to be practicing PTs who were willing and able to complete the electronic survey. The Academy of Orthopaedic Physical Therapy sent a single email invitation to potential participants. The email described the study and included a link to the survey that was open for one month. Participation was voluntary; consent to participate was implied when participants clicked "Yes" to begin the survey.

\section{SURVEY DESIGN AND CONTENT}

The survey was created specifically for the current study by the research team. The first step in the development of the survey was to identify relevant items. Over 30 items were generated to address the study aims. The research team reduced those items to approximately 20 items by eliminating similar or duplicate items and items considered unrelated to the aims. Using a judgmental approach, ${ }^{13}$ content validity was established with the research team and experts in the field. Pretesting of the mechanics of the survey was then conducted through the institution's Survey Research Center to ensure that the survey was functioning as intended. Additional pretesting was performed using practicing clinicians (PTs, athletic trainers, and a self-efficacy expert) to determine content validity. Because the survey was designed to assess practice habits and to seek the diverse perspectives of clinicians, internal consistency was not evaluated. For these kind of data, reliability analysis of internal consistency is difficult and not often performed. ${ }^{14,15}$ The final version of the electronic survey contained a minimum of 10 questions and used branching logic to populate 2-3 additional questions based on each respondent's previous answers. Therefore, not all questions in the survey were necessarily completed by all respondents because the number of questions depended on an individual's previous responses. A demographics section at the end of the survey asked participants to report their gender, date of birth, occupation, employment setting, years of experience, highest level of degree, and state of practice. The survey was administered through Qualtrics (Qualtrics, Inc, Provo, UT) and required 5-7 minutes to complete.

The survey included 3 questions to determine the importance of patient self-efficacy to PTs. The first question addressed the degree to which PTs believed that self-efficacy 
is important for patient adherence to exercise. Responses were rated on a 5-point Likert-like scale ranging from 0 (not important) to 4 (extremely important). The second question asked participants to select which patient barriers were typically related to patients not completing prescribed exercise. Specifically, PTs were asked to rank, in a drag and drop format, eight patient barriers (anxiety or depression, feelings of helplessness, forgetfulness, lack of time, lack of social support, low levels of activity at baseline, pain with exercise, and low self-efficacy), derived from the literature, on a scale from 1 (most often/common) to 8 (least often/ common). ${ }^{3,6}$ The third question, stemming from the second, asked participants to rank the patient barriers they felt most negatively influenced patient adherence using a similar scale, 1 (most influential) to 8 (least influential). For both questions, a lower score represented greater influence.

Two questions were included in the survey to determine how PTs assess and use patient self-efficacy. One question dealt with methods of assessment and allowed respondents to select any forms of assessment used (verbal discussion, observation, patient-reported outcomes, and other). The second question was open-ended and asked PTs to report how they used patient self-efficacy information after collecting it (Based on a patient's self-efficacy, how do you individualize treatment?).

Participants who indicated that they did not assess patient self-efficacy before prescribing HEPs were asked to identify what prevented them from doing so. Specifically, they were asked to select any barriers perceived from a list (e.g., not knowing how to assess, assessment would not change course of treatment, not sure what to do with the information after assessing, not knowing what self-efficacy is, time involved, or "other"). If the "other" option was selected, an open text box appeared to allow respondents to list additional barriers they encounter to assessing patient self-efficacy.

\section{DATA ANALYSIS}

Survey responses and demographic data were summarized descriptively [e.g., frequencies and percentages or mean (SD)]. A Friedman test was used to examine differences in participants' rankings of the 8 barriers. A Wilcoxon signed rank test was used to determine where differences existed between and order of perceived and observed patient barriers. Seven pairwise comparisons were performed, therefore, the significance level was set to .007. Statistical analyses were performed in SPSS version 24.0 (IBM SPSS, Armonk, NY, USA).

Open ended responses were independently coded by two authors (KJP and ASV) according to their relevance to the four hypothesized sources of self-efficacy: mastery experience, verbal or social persuasion, vicarious experience, and physiological or emotional state. ${ }^{8}$ In this study, previous successes with rehabilitation exercise, a mastery experience, was thought to shape one's beliefs in their abilities to adhere to HEPs. ${ }^{8}$ Phrases such as "build confidence," "patient properly demonstrates exercise," "goal setting," and "break down tasks," were placed in the mastery category. Verbal or social persuasion phrases include those such as "discussion with the patient," "provide encouragement or

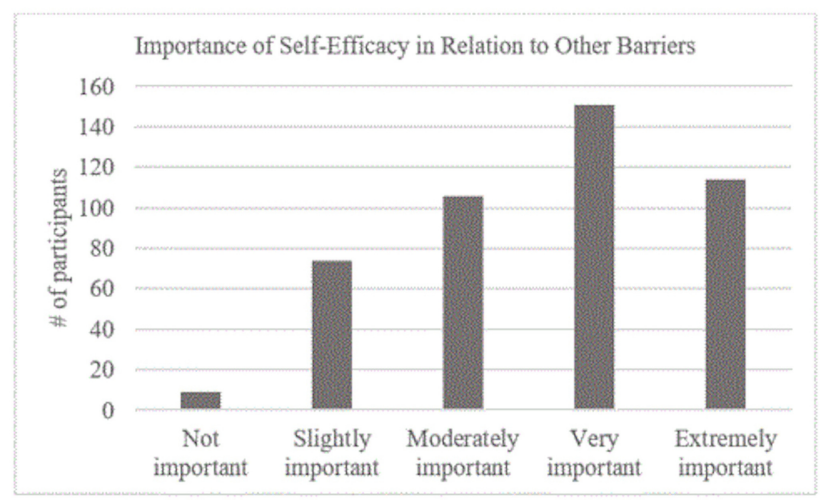

\section{Figure 1: Physical therapists perceived importance of self-efficacy}

positive feedback," and "use of cueing techniques" were placed in this category. The third category, vicarious experiences, include phrases such as "I demonstrate exercises," "show patients how to successfully complete an exercise," or "use of models" were placed in this category. The last category, physiological or emotional states, included phrases such as "patient education related to symptoms/ pain" and "reduce pain." Responses that did not fit into one of these categories were designated by an "Other" category. Codes assigned to the data by each rater were compared. In cases of discrepancy, a third author (ELU) was consulted to make the final decision.

\section{RESULTS}

The email invitation was sent to 17730 practicing PTs, and 462 surveys were completed (2.6\% response rate). Of the 545 who initiated the survey, 462 complete it in its entirety (84.8\% completion rate). On average, participants were $41 \pm 12$ years old and had $15 \pm 12$ years of work experience, (Range $=0.5-53$ ). Additional participant demographics are presented in Table 1.

Regarding the importance of patient self-efficacy, 58\% of PTs reported self-efficacy to be very (151/454) or extremely important (114/454) (Figure 1). Only 2\% (9/454) reported self-efficacy as not at all important.

Physical therapists differed significantly in how they ranked the identified patient barriers to exercise adherence $\left(\chi^{2}=892.06, \mathrm{df}=7, p<.001\right)$. As indicated in Table 2, rankings differed significantly among patient barriers with few exceptions. Lack of time was ranked as the most observed patient barrier to rehabilitation exercise adherence, followed by forgetting and having low levels of activity at baseline. Low self-efficacy was ranked fifth of the 8 patient barriers.

Physical therapists also ranked the same set of patient barriers in terms of which had the most negative influence on exercise adherence. Again, their rankings differed significantly ( $\chi^{2}=252.44, \mathrm{df}=7, p<.001$ ) (see Table 3 ). Physical therapists ranked the presence of anxiety or depression as having the most negative influence on adherence $(p<.007)$. Statistically, there were no significant differences $(\mathrm{P}>.001)$ 
Table 1: Participant characteristics $(n=462)$

\begin{tabular}{|c|c|c|}
\hline Demographics & & \\
\hline \multirow[t]{3}{*}{ Sex } & Female & 232 \\
\hline & Male & 228 \\
\hline & Not reported & 2 \\
\hline \multicolumn{3}{|c|}{ Level of education completed } \\
\hline & Doctorate & 340 \\
\hline & Masters & 66 \\
\hline & Bachelors & 35 \\
\hline & Ph.D. & 20 \\
\hline & Not reported & 1 \\
\hline \multicolumn{3}{|c|}{ Region of practice } \\
\hline & Midwest & 118 \\
\hline & West & 111 \\
\hline & Northeast & 98 \\
\hline & Southeast & 94 \\
\hline & Southwest & 33 \\
\hline & Not Reported & 8 \\
\hline \multicolumn{3}{|c|}{ Setting of practice } \\
\hline & Outpatient/private practice & 393 \\
\hline & Hospital & 79 \\
\hline & Education/research & 20 \\
\hline & Acute care & 17 \\
\hline & Home health & 14 \\
\hline & Professional sports & 13 \\
\hline & Government & 12 \\
\hline & Subacute care & 11 \\
\hline & Collegiate & 11 \\
\hline & Secondary school & 8 \\
\hline & Extended care & 7 \\
\hline & Industrial & 5 \\
\hline
\end{tabular}

Table 2: Friedman test results of what physical therapists observe to be barriers to patient exercise adherence

\begin{tabular}{|c|c|c|c|c|}
\hline Barriers & $\mathbf{N}$ & Mean ranks & SD & Group differences \\
\hline Lack of time & 460 & 2.51 & 2.15 & All \\
\hline Forgetting & 460 & 3.32 & 2.04 & All \\
\hline Low levels of activity at baseline & 460 & 3.55 & 2.01 & All \\
\hline Pain with exercise & 460 & 4.45 & 2.01 & All \\
\hline Low self-efficacy ${ }^{a}$ & 460 & 4.97 & 1.94 & All, except b \\
\hline Anxiety/depression ${ }^{b}$ & 460 & 5.32 & 1.94 & All, except a \& c \\
\hline Helplessness ${ }^{c}$ & 460 & 5.57 & 1.75 & All, except b \\
\hline Lack of social support & 460 & 6.33 & 1.71 & All \\
\hline
\end{tabular}

*A Wilcoxon Signed Rate test detected between which groups differences exist, this is indicated in the group differences column. Three barriers were assigned a letter as indicated by the superscript.

***A higher score indicates lower importance.

between self-efficacy, low levels of activity at baseline, feel- ings of helplessness, and increased pain during exercises for 
Table 3: Friedman test results of what physical therapists believe the most negatively influential to patient exercise adherence

\begin{tabular}{lcccc}
\hline Barriers & N & Mean rank & SD & Group differences \\
\hline Anxiety/depression & 458 & 3.54 & 2.12 & All \\
Low levels of activity at baseline $^{\mathrm{a}}$ & 458 & 3.99 & 2.17 & All, except b, c, d \\
Helplessness $^{\mathrm{b}}$ & 458 & 4.20 & 1.90 & All, except a, c, d \\
Pain with exercise $^{\mathrm{c}}$ & 458 & 4.26 & 2.21 & All, except a, b, d \\
Low self-efficacy $^{\mathrm{d}}$ & 458 & 4.30 & 2.10 & All, except a, b, c \\
Forgetting e $^{\text {ack of time }}{ }^{\mathrm{f}}$ & 458 & 5.00 & 2.26 & All, except f \\
Lack of social support & 458 & 5.02 & 2.71 & All, except e \\
\hline
\end{tabular}

*A Wilcoxon Signed Rate test detected between which groups differences exist, this is indicated in the group differences column. All barriers were assigned a letter as indicated by the superscript.

**A higher score indicates less influence on patient exercise adherence.

the second rank.

Regarding how PTs assess and use patient self-efficacy, 71\% (329/462) indicated that they assess patient self-efficacy for home exercise before prescribing an HEP (Figure 2). Half of the PTs reported using verbal discussion to assess patient self-efficacy. PTs also reported observing the patient (38\%), using patient self-report questionnaires (10\%), and using other methods (2\%) to assess patient self-efficacy. Eighty-nine (27\%) PTs identified using only 1 method to assess patients' self-efficacy, whereas 186 (57\%) PTs said they used 2 methods, and 53 (16\%) said that they used 3 or more. Verbal discussion and patient observation were selected together most frequently; $91 \%$ of those selecting 2 methods reported assessing self-efficacy with these techniques. Only 10 (3\%) participants reported using some other method to assess self-efficacy, and their responses were related to discussion with the patient or observing them complete the prescribed exercise.

Of the 328 PTs who reported assessing patient self-efficacy, 310 (94\%) indicated how they individualized treatment after assessment by responding to the open-ended prompt. This open-ended prompt allowed participants to write freely to expand on all treatments they may use to address patient self-efficacy. From these open ended responses, 362 treatments were extracted and 185 corresponded loosely to Bandura's theorized sources of self-efficacy. ${ }^{8}$ Table 4 presents frequency counts based on common themes. Roughly half of participants' responses were related to supporting patient self-efficacy through one or more of the sources of self-efficacy. Mastery experience (92/ $362,25 \%)$ was the most common method followed by verbal persuasion (62/362, 17\%), vicarious experience (19/362, $5 \%)$, and physiological state (12/362, 3\%).

Of the open-ended responses, $49 \%$ could not be directly related to any of Bandura's four ${ }^{8}$ sources of self-efficacy. Themes from these responses included individualization of HEPs based on patient preference or patient resources, modification of sets, repetitions, and type of exercise, or focused on nonspecific patient education. The other category consisted of statements regarding findings that would al-

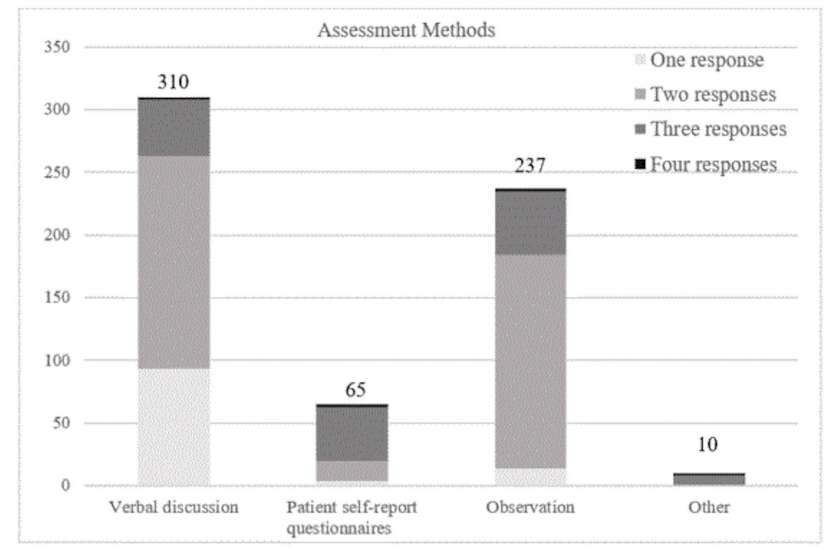

Figure 2: Methods of self-efficacy assessment used by physical therapists

ter treatment, not methods of individualization that can be tied to Bandura's sources of self-efficacy.

The last aim of the study was to examine factors that prevent PTs from assessing patient self-efficacy. In total, 134 respondents indicated they did not assess self-efficacy. Of those who reported barriers to assessing patient self-efficacy, 21\% (28/134) reported more than one barrier (i.e., 21 participants identified two barriers, and 7 identified three or more barriers for a $\mathrm{n}=170$ barriers reported). Of those, $39.4 \%(67 / 170)$ reported not knowing how to assess self-efficacy, 19\% (32/170) were not sure what to do with the information once self-efficacy was assessed, 16.5\% (28/170) reported other barriers to assessment, 14.1\% (24/170) reported that assessing self-efficacy would not change their practice, $10 \%(17 / 170)$ indicated that assessing self-efficacy took too much time, and 1\% (2/170) did not know what selfefficacy was (Figure 3 ). Of those who indicated that "other" barriers $(21 \%, 28 / 170)$ prevented them from assessing patient self-efficacy, the most common response was assessment of self-efficacy was conducted at another time or they do not believe that self-efficacy is important enough to as- 
Table 4: Themes extracted on how physical therapists individualize home exercise programs based on selfefficacy assessment

\begin{tabular}{|c|c|c|}
\hline Theme & $\begin{array}{l}\text { Frequency (Out } \\
\text { of } 362 \text { responses) }\end{array}$ & Example of participant response \\
\hline $\begin{array}{l}\text { Mastery } \\
\text { experience }\end{array}$ & 92 & $\begin{array}{l}\text { "Try to make home exercises that I have observed them successfully perform within the } \\
\text { therapy session." } \\
\text { "Select exercises they can perform confident and successfully over time during visits; } \\
\text { begin with } 1 \text { simple exercise to begin." }\end{array}$ \\
\hline $\begin{array}{l}\text { Verbal/ } \\
\text { social } \\
\text { persuasion }\end{array}$ & 62 & $\begin{array}{l}\text { "Provide encouragement." } \\
\text { "Reinstruct as needed." } \\
\text { "Bring a family member in to help." } \\
\text { “...will follow up } 24 \text { hours later by email/phone." }\end{array}$ \\
\hline $\begin{array}{l}\text { Vicarious } \\
\text { experience }\end{array}$ & 19 & $\begin{array}{l}\text { "I demonstrate a successful completion." } \\
\text { "...give written material with pictures and a web address for videos." }\end{array}$ \\
\hline $\begin{array}{l}\text { Physiological } \\
\text { state }\end{array}$ & 12 & $\begin{array}{l}\text { "Prioritize based on symptom management." } \\
\text { "Teach them how specific exercises can effect them." } \\
\text { "Emphasis that they CANNOT do any harm that movement is good, they are not hurting } \\
\text { anything." }\end{array}$ \\
\hline Other & 177 & $\begin{array}{l}\text { "I may change visit frequency or modify number/type of exercises prescribed for home." } \\
\text { "Limit the number of exercises." } \\
\text { "Modify home exercise program in order for them to complete it on a regular basis, such } \\
\text { as number of exercises, per day, work schedule, family demands." } \\
\text { "Observe patient problem solve." } \\
\text { "Make sure it can be completed with available or no equipment." } \\
\text { "2 week home exercise program trial to assess success." }\end{array}$ \\
\hline
\end{tabular}

sess. When compared to those who do assess self-efficacy for HEPs, there were no statistically significant differences between groups for age, sex, or years of clinical experience.

\section{DISCUSSION}

The current study surveyed practicing PTs to determine their assessment and use of self-efficacy in musculoskeletal rehabilitation when prescribing HEPs. Just over half of participants found self-efficacy to be very to extremely important for patient adherence. Although the PTs surveyed in this study did not rank self-efficacy as the most important barrier to adherence (i.e., time contraints was ranked highest, and anxiety and depression was ranked as most adversely associated with adherence), almost three-quarters of the PTs participating in the study reported that they assess patients' self-efficacy for HEPs before prescribing programs. Their assessments occur mainly through verbal discussions with or observations of the patient. However, over one quarter of paticipants reported that they did not assess self-efficacy. These findings suggest the need for better education of clinicians about the role of self-efficacy in guid-

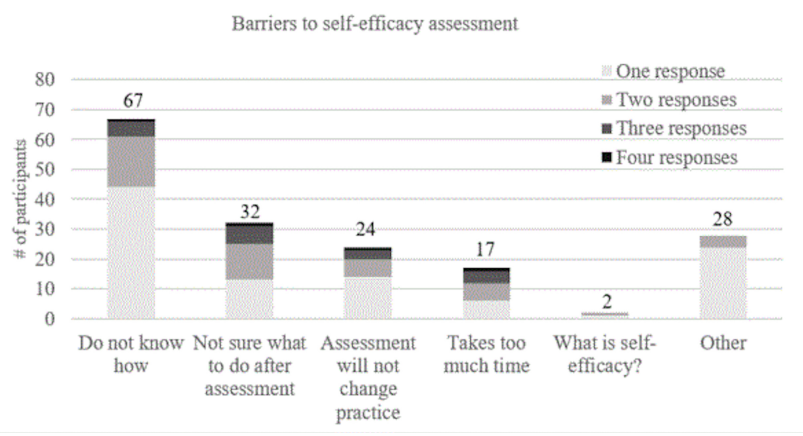

Figure 3: Physical therapist's barriers to self-efficacy assessment

ing patient behavior.

Previous research has shown self-efficacy to be a moderate predictor of patient adherence and an influencer of patient behavior throughout the rehabilitation process. ${ }^{16-19}$ The clinical implications of such research suggest that clinicians should focus on patient self-efficacy to improve adherence and outcomes. $6,7,16$ Results of the current study 
support this evidence; the surveyed PTs believed self-efficacy was an important concept in musculoskeletal rehabilitation. These findings are also consistent with those from a qualitative study of 5 PTs who also noted the important effect of self-efficacy on patient adherence to treatment. ${ }^{20}$ Although anxiety and depression stood out in the rankings as the most negatively influential barrier hindering patient adherence, low self-efficacy ranked similarly with other barriers (e.g., pain while exercising, helplessness, and low levels of activity at baseline) as next most influential. Physical therapists may not be able to treat anxiety or depression without additional training, but they do have the ability to influence patient self-efficacy. Ultimately, understanding which barriers clinicians can successfully address is important when trying to improve patient adherence to HEPs.

When PTs ranked the patient barriers to exercise that they observed most often, self-efficacy was ranked the same as 3 other barriers falling in at ranks 2-5; lack of time was ranked as the most prevalent barrier. Patients who are considered noncompliant have previously reported that they lacked time to exercise or the exercises did not fit into their daily schedules. ${ }^{3}$ As such, the PT should ask the patient about time constraints before prescribing an HEP. MedinaMirapeix et al. ${ }^{21}$ examined adherence to HEPs with varying frequency and durations to identify whether adherence rates were different between patients with neck or back pain. They found prescribed exercises should be limited to 3 exercises or fewer because patients had lower odds of being adherent to their HEP when more exercises were prescribed. ${ }^{21}$ Another study examined the adherence of 15 older adults to HEPs consisting of 2,5 , or 8 exercises. ${ }^{22}$ The researchers found that older adults were more compliant with 2 exercises. ${ }^{22}$ Time constraints are likely to be associated with self-efficacy for HEP adherence. When patients are given too many exercise tasks, they may become unduly frustrated or fail to remember how to perform them. Therefore, clinicians should consider the patient's time when trying to improve adherence to HEPs. Further, they should try to limit HEPs to 2-3 key exercises to facilitate adherence. Limiting exercises prescribed, as well as assessing patient self-efficacy for HEPs is of great importance for patient adherence.

In the current study, it was expected that patient observation would be the most common assessment method reported for assessing self-efficacy. However, verbal discussion with the patient was most commonly reported and often in combination with patient observation. In the literature, assessment of self-efficacy has typically included the use of self-report scales and questionnaires. ${ }^{23}$ A recent systematic review ${ }^{23}$ compiled methods of self-efficacy assessment to identify the variety of reliable and valid scales currently used in musculoskeletal rehabilitation. The authors did not identify verbal discussion or observation of the patient as reliable or valid methods of assessment. If PTs are not using assessment methods with sound psychometric properties, the quality of their results may be limited. As Bandura has noted, there are no strict behavioral markers for high or low self-efficacy. ${ }^{24}$ Clinicians can make incorrect inferences about a patient's self-efficacy from verbal discussion and direct observation. Using these as the sole methods of self-efficacy assessment may not provide sufficient information about the patient's cognitive self-judgment.

In the current study, only $10 \%$ of PTs reported using patient-reported scales or questionnaires. Because patient-reported outcome measures are increasingly used in clinical practice as a self-report of function, ${ }^{25}$ it is surprising that barriers to adherence would not be addressed using the same methodology. That is, until recently, there was not a scale designed to specifically assess patient self-efficacy for HEPs. Picha et. $\mathrm{al}^{26}$ developed and established the psychometric properties of the Self-Efficacy for Home Exercise Programs Scale. This 12-item scale was designed to increase clinician assessment of patient self-efficacy for HEPs to enhance patient centered care. Clinicians should be aware of their options for assessment of patient self-efficacy to effectively track progress and improve patient care.

Although successful interventions to improve self-efficacy have been identified $7,9,11,27$ the results of this study suggest that PTs are not utilizing this evidence in practice. It may be that they are unfamiliar with such interventions. Three hundred and sixty two treatments were extracted from the open-ended responses addressing individualized treatment after assessment. Of those, half did not address self-efficacy as proposed by Bandura. ${ }^{8}$ This finding suggests that clinicians may not know how to effectively address or promote self-efficacy in their patients. Many of the responses were well removed from the construct of self-efficacy and primarily indicated that PTs individualized treatment based on other barriers. Individualizing treatments based on other patient barriers shouldn't be perceived as incorrect, but speaks to the need for more education on the value of promoting self-efficacy to drive adherence. Given that previous studies have found promising results related to self-efficacy, 7,9,11,27 incorporating the sources of self-efficacy into rehabilitation would be benefical for those wanting to improve patient self-efficacy. For example, working with the patient to set goals, providing positive feedback, and including family or friends as additional social support can be effective strategies to improve self-efficacy. $7,9,28$

Over a fourth of PTs in the current study reported they do not assess self-efficacy for HEPs. Of the PTs who did not assess self-efficacy, most report not knowing how to assess self-efficacy for HEPs and almost a quarter did not know what to do with the information once assessed. Perhaps the educational programs of these PTs did not cover this material sufficiently, or perhaps not knowing how to assess self-efficacy for HEPs arises from a lack of suitable instruments to assess it. ${ }^{23}$ In a systematic review, ${ }^{23}$ the authors were unable to find a self-efficacy scale that was task specific to HEPs. In another study, when a general exercise scale was used to evaluate self-efficacy for home exercise, no relationship between home exercise and adherence was found. ${ }^{29}$ Because self-efficacy is task and situation specific, scales need to reflect the tasks of interest and relevant to the context. One study examined the barriers to use of patient-reported outcomes measures and found that the most common barrier to assessment was time: time for patients to complete the assessment, and time for clinicians to analyze or score it. ${ }^{30}$ However, only $11 \%$ of respondents in the current study indicated time as a barrier to assessing patient self-efficacy.

Since most of the participants perceived patient self-ef- 
ficacy as important, knowing how to assess self-efficacy for HEPs in an efficient and valid manner is important. Another reason clinicians have previously reported for not using patient-reported outcome measures is the belief that such measures are only useful for research purposes ${ }^{30}$ or that the results would not change their practice. ${ }^{31}$ Similarly, almost a fifth of participants indicated that assessing self-efficacy for HEPs would not change their practice. In a study by Stickler, ${ }^{20}$ PTs reported that self-efficacy does affect adherence, but they believed that gaining self-efficacy was the patient's responsibility. However, evidence suggests ${ }^{6,7}$ that self-efficacy is a barrier that can be influenced by the clinician and is a predictor of rehabilitation adherence. Therefore, PT education programs should stress the assessment of self-efficacy and interventions to improve it, especially for HEPs.

The current study had some limitations. The survey response rate was low. Practicing PTs were recruited from the Academy of Orthopaedic Physical Therapy as a sample of convenience; therefore, the results may be generalizable to only that population. These factors limit the external validity of the results. Physical therapists in other sections of the association or in other rehabilitation areas may have different perceptions of self-efficacy as a barrier and of the use of patient self-efficacy in practice. Additionally, this study does not address the overlap and direct correlations these 8 barriers have with each other. Self-efficacy specifically has direct correlations with depression ${ }^{32}$ and therefore, PT's may not be equipped to address self-efficacy in combination with underlying mental health conditions. The selected data collection method provides a helpful, yet limited level of detail. Conducting lengthier conversations with clinicians would enable a more comprehensive understanding of how they can support patients' self-efficacy.

\section{CONCLUSION}

Self-efficacy is an important construct influencing patient care. However, it may not be the most commonly observed or perceived as a largely influential patient barrier by PTs. The findings of this study suggested a few key concerns with current self-efficacy assessment and utilization when trying to improve patient adherence to HEPs. First, for this group of respondents, assessment of self-efficacy for HEPs was primarily performed through verbal discussion or observation of the patient; neither of these methods have been found to be reliable or valid for assessment. Second, about half of clinicians who reported assessing self-efficacy for HEPs may not be adequately addressing patient self-efficacy within their treatment plans. Although almost half of the PTs surveyed used a theorized source of self-efficacy in their treatment plans, just as many did not describe using one of the known strategies for changing patient self-efficacy. This provides a rich opportunity for PT professional development. Lastly, a number of PTs who reported not assessing self-efficacy for HEPs conveyed that they did not know how to assess this construct. This may be due to a lack of instrumentation or education. Future research should focus on utilization of self-efficacy instruments, such as the Self-Efficacy for Home Exercise Programs Scale, that assesses self-efficacy for HEPs in clinical practice and should work to improve implementation strategies for successful self-efficacy interventions.

The University of Kentucky IRB has approved this study.

\section{CONFLICTS OF INTEREST}

The authors report no conflicts of interest to disclose.

Submitted: March 13, 2020 CDT, Accepted: October 10, 2020 CDT 


\section{REFERENCES}

1. Pizzari T, McBurney H, Taylor NF, Feller JA. Adherence to anterior cruciate ligament rehabilitation: a qualitative analysis. J Sport Rehabil. 2002;11:90-102.

2. Kolt GS, McEvoy JF. Adherence to rehabilitation in patients with low back pain. Man Ther.

2003;8(2):110-116.

3. Sluijs EM, Kok GJ, van der Zee J. Correlates of exercise compliance in physical therapy. Phys Ther. 1993;73(11):771-782; discussion 783-6.

4. Essery R, Geraghty AW, Kirby S, Yardley L. Predictors of adherence to home-based physical therapies: a systematic review. Disabil Rehabil. 2017;39(6):519-534. doi:10.3109/09638288.2016.1153 $\underline{160}$

5. Pisters MF, Veenhof C, Schellevis FG, Twisk JW, Dekker J, De Bakker DH. Exercise adherence improving long-term patient outcome in patients with osteoarthritis of the hip and/or knee. Arthritis Care Res. 2010;62(8):1087-1094. doi:10.1002/acr.2018 2

6. Jack K, McLean SM, Moffett JK, Gardiner E. Barriers to treatment adherence in physiotherapy outpatient clinics: a systematic review. Man Ther. 2010;15(3):220-228. doi:10.1016/i.math.2009.12.004

7. Rajati F, Sadeghi M, Feizi A, Sharifirad G, Hasandokht T, Mostafavi F. Self-efficacy strategies to improve exercise in patients with heart failure: a systematic review. ARYA Atheroscler. 2014;10(6):319-333

8. Bandura A. Self-Efficacy. In: Encyclopedia of Human Behavior. Vol 4. New York: Academic Press; 1994:71-81.

9. Coppack RJ, Kristensen J, Karageorghis CI. Use of a goal setting intervention to increase adherence to low back pain rehabilitation: a randomized controlled trial. Clin Rehabil. 2012;26(11):1032-1042. doi:10.117 7/0269215512436613

10. Heslin PA, Klehe UC. Self-efficacy. In: Rogelberg SG, ed. Encyclopedia of Industrial/Organizational Psychology. Vol 2. Thousand Oaks: Sage; 2006:705-708.

11. Gohner W, Schlicht W. Preventing chronic back pain: evaluation of a theory-based cognitivebehavioural training programme for patients with subacute back pain. Patient Educ Couns. 2006;64(1-3):87-95. doi:10.1016/j.pec.2005.11.018
12. Storheim K, Brox JI, Holm I, Koller AK, Bo K. Intensive group training versus cognitive intervention in sub-acute low back pain: short-term results of a single-blind randomized controlled trial. $J$ Rehabil Med. 2003;35(3):132-140.

13. Taherdoost $\mathrm{H}$. Validity and reliability of the research instrument; how to test the validation of a questionnaire/survey in a research. How to Test the Validation of a Questionnaire/Survey in a Research (August 10, 2016). 2016.

14. Weber ML, Welch CE, Parsons JT, Valovich McLeod TC. School nurses' familiarity and perceptions of academic accommodations for student-athletes following sport-related concussion. J Sch Nurs. 2015;31(2):146-154. doi:10.1177/105984051 $\underline{4540939}$

15. Williams RM, Welch CE, Weber ML, Parsons JT, Valovich McLeod TC. Athletic trainers' management practices and referral patterns for adolescent athletes after sport-related concussion. Sports Health. 2014;6(5):434-439. doi:10.1177/1941738114545612

16. Mendonza M, Patel H, Bassett S. Influences of psychological factors and rehabilitation adherence on the outcome post anterior cruciate ligament injury/ surgical reconstruction. NZ J Physio. 2007;35(2):62-71.

17. Grindley EJ, Zizzi SJ, Nasypany AM. Use of protection motivation theory, affect, and barriers to understand and predict adherence to outpatient rehabilitation. Phys Ther. 2008;88(12):1529-1540. do i:10.2522/ptj.20070076

18. Oliver K, Cronan T. Predictors of exercise behaviors among fibromyalgia patients. Prev Med. 2002;35(4):383-389.

19. Martos-Méndez MJ. Self-efficacy and adherence to treatment: the mediating effects of social support. $J$ Behav Health Soc Issues. 2015;7(2):19-29. doi:10.5460/ ibhsi.v7.2.52889

20. Stickler K. Adherence to physical therapy: a qualitative study. J Student Phys Ther Res. 2015;8(1):32-40.

21. Medina-Mirapeix F, Escolar-Reina P, GascónCánovas JJ, Montilla-Herrador J, Jimeno-Serrano FJ, Collins SM. Predictive factors of adherence to frequency and duration components in home exercise programs for neck and low back pain: an observational study. BMC Musculoskelet Disord. 2009;10(1):155. doi:10.1186/1471-2474-10-155 
22. Henry KD, Rosemond C, Eckert LB. Effect of number of home exercises on compliance and performance in adults over 65 years of age. Phys Ther. 1999;79(3):270-277. doi:10.1093/ptj/79.3.270

23. Picha KJ, Jochimsen KN, Heebner NR, et al. Measurements of self-efficacy in musculoskeletal rehabilitation: a systematic review. Musculoskeletal Care. 2018;16(4):471-488. doi:10.1002/msc.1362

24. Bandura A. Self-Efficacy: The Exercise of Control. New York: W.H. Freemand and Company; 1997.

25. Kyte DG, Calvert M, van der Wees PI, ten Hove R, Tolan S, Hill JC. An introduction to patient-reported outcome measures (PROMs) in physiotherapy. Physiotherapy. 2015;101(2):119-125. doi:10.1016/i.ph ysio.2014.11.003

26. Picha KJ, Lester M, Heebner NR, et al. The SelfEfficacy for Home Exercise Programs Scale: Development and Psychometric Properties. J Orthop Sports Phys Ther. 2019;49(9):647-655. doi:10.2519/jos pt.2019.8779

27. Taylor SJ, Carnes D, Homer K, et al. Novel threeday, community-based, nonpharmacological group intervention for chronic musculoskeletal pain (COPERS): A randomised clinical trial. PLoS Med. 2016;13(6):e1002040. doi:10.1371/journal.pmed.1002 $\underline{040}$
28. Levy AR, Polman RCJ, Clough PJ. Adherence to sport injury rehabilitation programs: an integrated psycho-social approach. Scand J Med Sci Sports. 2008;18(6):798-809. doi:10.1111/j.1600-0838.2007.00 704.X

29. Cheung C, Wyman JF, Savik K. Adherence to a yoga program in older women with knee osteoarthritis. J Aging Phys Act. 2016;24(2):181-188. d oi:10.1123/japa.2015-0048

30. Al-Muqiren TN, Al-Eisa ES, Alghadir AH, Anwer S. Implementation and use of standardized outcome measures by physical therapists in Saudi Arabia: barriers, facilitators and perceptions. BMC Health Serv Res. 2017;17(1):748. doi:10.1186/s12913-017-2693-2

31. Espallargues M, Valderas JM, Alonso J. Provision of feedback on perceived health status to health care professionals: a systematic review of its impact. Med Care. 2000;38(2):175-186.

32. Kavanagh D, Schwarzer R. Self-Efficacy: Thought Control of Action. New York, NY: Routledge Taylor and Francis Group; 1992. 